\title{
Effects of 1-methylcyclopene and controlled-atmosphere treatment on the quality and antioxidant capacity of blueberries during storage
}

\author{
Liangjie $\mathrm{BA}^{1 \sharp}$, Donglan $\mathrm{LUO}^{1 *}$, Ning $\mathrm{JI}^{1}$, Sen $\mathrm{CAO}^{1}$, Chao $\mathrm{MA}^{1}$, Peng $\mathrm{ZHANG}^{2}$, Rui WANG ${ }^{1 *}$
}

\begin{abstract}
The effects of 1-methylcyclopropene (1-MCP) treatment and controlled-atmosphere (CA) storage and their combination on quality and antioxidant capacity of postharvest blueberries were evaluated here. To investigate the most appropriate approach for maintaining fruit quality, blueberries were subjected to four different treatments, a control (CK), 1-MCP, $3 \% \mathrm{O}_{2}+10 \%$ $\mathrm{CO}_{2}(\mathrm{CA})$, and 1-MCP combined with $3 \% \mathrm{O}_{2}+10 \% \mathrm{CO}_{2}(1-\mathrm{MCP}+\mathrm{CA})$, then stored for 80 days at $0{ }^{\circ} \mathrm{C}$. It was found that the applications of 1-MCP, CA and 1-MCP + CA were effective at delaying the increase in weight loss and inhibiting the decrease in firmness, total soluble solids (TSS) contents and titratable acidity (TA) contents. In addition, 1-MCP, CA and 1-MCP + CA treatment could significantly suppress MDA accumulation and relative electrolytic leakage promotion. Moreover, the production of reactive oxygen species (ROS), such as $\mathrm{O}_{2}^{-}$and $\mathrm{H}_{2} \mathrm{O}_{2}$, was reduced by all the treatment, which was associated with increased activities of antioxidant enzymes including superoxide dismutase (SOD), catalase (CAT), and ascorbate peroxidase (APX). Taken together, our findings indicate 1-MCP, CA and 1-MCP + CA have potential applications in maintaining the quality and improving the antioxidant capacity of harvested blueberries, and 1-MCP + CA is the most effective treatment.
\end{abstract}

Keywords: 1-MCP; CA storage; fruit quality; antioxidant capacity; blueberry.

Practical Application: Maintain fruit quality and improve antioxidant of blueberries using 1-MCP and CA treatment.

\section{Introduction}

The fruits of blueberries (Vaccinium spp.) are popular to consumers because they contain an abundance of antioxidant substances, including anthocyanins, folic acid, flavonoids and dietary fibre (Saxena et al., 2013). However, since the harvest of blueberries occurs from June to August, during which time the temperature and humidity are high, blueberries are highly susceptible to mechanical damage and pathogenic bacteria after harvest, leading to fruit deterioration and shelf-life shortening (Hancock et al., 2008; Xie et al., 2018). Therefore, understanding physiological changes and identifying appropriate techniques for harvested blueberries are very important for maintaining quality and prolonging shelf-life.

Reactive oxygen species (ROS) such as superoxide radicals $\left(\mathrm{O}_{2}^{-}\right)$, $\mathrm{OH}^{-}$(hydroxyl radical) and $\mathrm{H}_{2} \mathrm{O}_{2}$ (hydrogen peroxide) are involved in cell membrane integrity and stability (Chen et al., 2017). The scavenging of excess ROS relies on the action of various antioxidant enzymes, including superoxide dismutase (SOD), catalase (CAT), peroxidase (POD) and ascorbate peroxidase (APX), and ROS-scavenging substances, such as flavonoids, glutathione (GSH), phenolics, and ascorbic acid (AsA). These activities play important roles in maintaining the redox balance and further influence the quality of harvested fresh fruits (Li et al., 2017; Lin et al., 2020). Thus, the rate of ROS production and the activities of ROS-scavenging enzymes and substances, which are closely associated with fruit quality, are often monitored during fruit storage (Lin et al., 2014). 1-Methylcyclopropene (1-MCP) is a well-known ethylene repressor that can inhibit ethylene perception and reduce ethylene effects in plant tissues to delay ripening, softening and senescence periods $(\mathrm{Oz} \&$ Ulukanli, 2014). 1-MCP is widely used in prolonging the shelflife of postharvest horticultural crops species such as broccoli, cucumber (Nilsson, 2005) and pepper (Cao et al., 2012) due to its advantages, including its low required dose, safety and high efficiency. Blaker \& Olmstead (2014) demonstrated that 1-MCP treatment five days prior to harvest decreased the firmness of southern highbush blueberries after harvest. Tao et al. (2017) demonstrated that 1-MCP treatment inhibited the rate of rotting, the weight loss and the MDA content while enhancing both antioxidant enzyme activities and the contents of soluble sugars and titratable acid (TA). Maclean \& Nesmith (2011) evaluated the effects of 1-MCP treatment on rabbiteye blueberries, which resulted in stimulation of ethylene production but had minimal effects on TSS and TA contents. Xu \& Liu (2017) reported that 1-MCP, UV-C irradiation, and their combination (1-MCP +UV$\mathrm{C}$ irradiation) on Berkeley blueberries reduced the respiration rate, ethylene production, decay incidence, and MDA content; inhibited the softness, colour, titratable acid, and soluble solids content; promoted the anthocyanin content; delayed the increase in peroxidase (POD) and phenylalanine ammonia lyase (PAL) activities; and postponed the decrease in catalase (CAT) activity. Moreover, Chiabrando \& Giacalone (2011) found that the application of 1-MCP on highbush blueberries delayed weight loss during storage. Significantly higher antioxidant activity in the 1 -MCP treatment was observed at 7 and 28 days of storage. 
$\mathrm{O}_{2} / \mathrm{CO}_{2}$ controlled-atmosphere (CA) storage has been identified as being effective for preserving postharvest fruit quality. Previous studies have demonstrated that the shelf-life extension of highbush blueberries can be attributed to a controlled atmosphere $\left(3 \mathrm{kPaO}_{2}+\right.$ $\left.11 \mathrm{kPa} \mathrm{CO}_{2}\right)$ (Chiabrando \& Giacalone, 2011). It was reported that $50 \% \mathrm{O}_{2}+50 \% \mathrm{CO}_{2}$ treatment of broccoli delayed its senescence by inhibiting increases in the $\mathrm{O}_{2}^{-}$. production rate, $\mathrm{H}_{2} \mathrm{O}_{2}$ content and respiration rate and by maintaining both the levels of ATP and energy charge (Li et al., 2016). Van de Velde et al. (2019) suggested that $90 \% \mathrm{O}_{2}+10 \% \mathrm{CO}_{2}$ could be a potential approach to promote bioactivity within strawberry fruits. In addition, the $\mathrm{CA}$ condition of $3 \mathrm{kPa} \mathrm{O}_{2}+6 \mathrm{kPa} \mathrm{CO}$ was suggested to have higher efficacy in retaining the quality of fresh-cut jackfruit bulbs (Saxena et al., 2013). Chiabrando \& Giacalone (2011) reported that the shelf-life of highbush blueberries could be extended using 1-MCP treatment and storage in a controlled atmosphere; while these authors monitored various quality parameters, such as weight loss, titratable acidity, firmness and anthocyanin content, they did not analyse the changes in enzymatic antioxidants in the blueberries. In this study, the potential of 1-MCP, CA and their combination for maintaining Powderblue blueberries was investigated during an eighty-day storage period at $0{ }^{\circ} \mathrm{C}$. Quality parameters, including weight loss, firmness and TSS content, were evaluated. Moreover, the effects of different treatments on the relative electrolytic leakage, MDA content, and ROS production and scavenging system were explored.

\section{Materials and methods}

Blueberries used in this study were hard-harvested in June 2019. The experiment was conducted in accordance with the harvest season of blueberries (from June to August) in the region of Guizhou, China.

\subsection{Fruit material and treatments}

Fully mature blueberries (Vaccinium corymbosum L. cv. Powderblue), whose colour had completely changed to blue (100\% blue), were gently harvested by hand between 9 and 11 a.m. from a planting station in Guizhou Province, China. Blueberries with uniform size and maturity and those free of disease or mechanical damage were selected. In total, $125 \mathrm{~g}$ of selected fruits was packaged into uniform pierced polyethylene terephthalate (PET) punnets. More than 600 punnets were prepared for further use. All the fruits were then immediately transported by automobile to the lab.

A portion of the blueberry samples (120 punnets) were subjected to assays on day 0 . These 120 punnets were divided equally into four groups, and each group contained 30 punnets, representing three replicates. Additional blueberries were selected and separated into four experimental groups.

The control group and CA group of blueberry samples (each containing 120 punnets) were placed in a $1 \mathrm{~m}^{3}$ enclosed space, which was sealed with polyethylene curtains ( $0.08 \mathrm{~mm}$ thick). The fruits were exposed to air at $22^{\circ} \mathrm{C}$ for $24 \mathrm{~h}$, and then the fruits were immersed in distilled water immediately after treatment through a sterile sieve for $5 \mathrm{~min}$; afterward, they were air dried until the surface water evaporated (Chiabrando \& Giacalone, 2011).

The 1-MCP group and 1-MCP+CA group of blueberry samples (each containing 120 punnets) were placed in another
$1 \mathrm{~m}^{3}$ enclosed space and exposed to $1.0 \mu \mathrm{L} \cdot \mathrm{L}^{-1} 1-\mathrm{MCP}$ at $22^{\circ} \mathrm{C}$ for $24 \mathrm{~h}$. The residual gas was displaced by the distilled water as previously described.

All blueberries were precooled in a refrigerator at $0{ }^{\circ} \mathrm{C}$ for approximately $8 \mathrm{~h}$. The control group and 1-MCP group of blueberries were then stored under regular cold-storage conditions $\left(0^{\circ} \mathrm{C}, 90 \%\right.$ $\mathrm{RH})$ for 80 days. The CA group and 1-MCP+CA group were stored under controlled-atmosphere (CA) conditions $\left(0{ }^{\circ} \mathrm{C}, 90 \%\right.$ relative humidity $(\mathrm{RH}), 3 \% \mathrm{O}_{2}+10 \% \mathrm{CO}_{2}$ ) for 80 days. CA conditions were achieved using a gas mixer (MAP Mix 9000, PBI-Dansensor, Denmark) according to the manufacturer's instructions, the gas mixer was used to mix the desired concentrations of $\mathrm{O}_{2}$ and $\mathrm{CO}_{2}$, and the gas mixtures were stored in buffer tanks and pumped into the CA chambers as a continuously flowing stream $\left(20 \mathrm{~mL} \cdot \mathrm{min}^{-1}\right)$ according to the methods of Saxena et al. (2013). The gas composition of CA chambers was monitored periodically by a gas analyser (MAP Check Combi, PBI-Dansensor, Denmark). Fruit samples (four groups, each containing 30 punnets) were taken every 20 days for physiological and biochemical experiments. All assessments were conducted in triplicate, and the fruits were completely randomized for the control and other treatments.

\subsection{Weight loss and firmness}

The firmness of the blueberry samples was determined for 30 individual fruit per treatment using a physical property tester (TA-XT Plus, Stable Micro Systems., Ltd., UK), which was equipped with a dynamometer with a $5 \mathrm{~mm}$ diameter probe at a constant speed of $0.5 \mathrm{~mm} \cdot \mathrm{s}^{-1}$, and the results were expressed in grams $(\mathrm{g})$.

Weight loss was measured based on the methods of Han et al. (2015), with slight modifications. Weight loss was determined for 30 individual fruits per treatment and calculated according to the following formula using an electronic balance with a precision of $0.001 \mathrm{~g}$ : weight loss = (initial fruit weight - final fruit weight $) /$ initial fruit weight. The results were expressed as percentages.

\subsection{TSS and TA contents}

Total soluble solids (TSS) of fruit sample juice were measured with a hand-held refractometer (PAL-1, Atago, Ltd., Japan) according to the methods of Han et al. (2015), and the results were expressed as percentages.

The titratable acidity (TA) of fruit sample juice was measured based on the methods of Li et al. (2018). The TA was measured with a $\mathrm{pH}$ meter (PH610, Wiggens, Ltd., Germany) by titrating with diluted juice with $0.1\left(\mu \mathrm{mol} \cdot \mathrm{L}^{-1}\right) \mathrm{NaOH}$. A pH of 8.1 was the end point, and the results were expressed as percentages.

\subsection{Relative electrolyte leakage and MDA content}

The relative electrolyte leakage was measured as described by Wang et al. (2014). Ten discs from ten blueberries were washed with distilled water and then immersed in a tube containing $40 \mathrm{~mL}$ of distilled water for $3 \mathrm{~h}$ at room temperature. The initial electrolyte leakage (L1) was measured by a conductivity meter. The tubes were then heated at $95{ }^{\circ} \mathrm{C}$ for $30 \mathrm{~min}$, and the final electrolyte leakage (L2) was determined after the boiled solution had cooled. The results were calculated as L1/L2 and ultimately expressed as percentages. 
The MDA content was determined using the methods of Wang et al. (2014). Frozen blueberry tissues $(2.0 \mathrm{~g})$ were homogenized in $5 \mathrm{~mL}$ of $0.1 \%$ trichloroacetic acid (TCA) solution. The homogenate was then centrifuged at $10,000 \times g$ for $20 \mathrm{~min}$. Two millilitres of the supernatant was mixed with $2 \mathrm{~mL}$ of $10 \%(\mathrm{w} / \mathrm{v})$ TCA solution containing $0.67 \%(\mathrm{w} / \mathrm{v})$ thiobarbituric acid (TBA). The mixture was subsequently heated to $100{ }^{\circ} \mathrm{C}$ for 20 minutes, cooled and then centrifuged at $10,000 \times g$ for $10 \mathrm{~min}$. The supernatant was subsequently collected and quantified spectrophotometrically at 450, 532 and $600 \mathrm{~nm}$ as previously described (Wang et al., 2014). The results were expressed in micromoles per gram.

\section{$2.5 \mathrm{O}_{2}^{-\cdot}$ production rate and $\mathrm{H}_{2} \mathrm{O}_{2}$ content}

The superoxide anion $\left(\mathrm{O}_{2}^{-}\right)$production rate was measured according to a modified method of Zhou et al. (2014). Five grams of blueberry tissue from 10 fruits was homogenized with $20 \mathrm{~mL}$ of $50 \mathrm{mM}$ sodium phosphate buffer ( $\mathrm{pH} 7.8$ ) consisting of $1 \mathrm{mM}$ EDTA, and the homogenate was centrifuged at $12,000 \times g$ for $15 \mathrm{~min}$. Afterwards, $1 \mathrm{~mL}$ of the supernatant, $1 \mathrm{~mL}$ of $50 \mathrm{mM}$ sodium phosphate buffer ( $\mathrm{pH} 7.8$ ) and $1 \mathrm{~mL}$ of $10 \mathrm{mM}$ ammonium hydroxychloride were mixed together. After incubation at $25^{\circ} \mathrm{C}$ for $20 \mathrm{~min}, 1 \mathrm{~mL}$ of the reaction mixture was added to equal volumes of $17 \mathrm{mM}$ aminobenzene sulfonic acid and $7 \mathrm{mM}$ naphthalene using diethyl ether to eliminate interference caused by the pigment, followed by further incubation at $25^{\circ} \mathrm{C}$ for $20 \mathrm{~min}$. Absorbance of the aqueous phase was measured at $530 \mathrm{~nm}$. The results were expressed in micromoles per minute per gram.

The $\mathrm{H}_{2} \mathrm{O}_{2}$ content was determined according to the methods of Zhou et al. (2014), with slight modifications. One gram of blueberry tissues from 10 fruits was homogenized with $6 \mathrm{~mL}$ of cooled acetone. The mixture was then centrifuged at $12,000 \times g$ for $10 \mathrm{~min}\left(4^{\circ} \mathrm{C}\right)$. One millilitre of the supernatant, $0.1 \mathrm{~mL}$ of $5 \% \mathrm{Ti}\left(\mathrm{SO}_{4}\right)_{2}$ and $0.2 \mathrm{~mL}$ of $\mathrm{NH}_{4} \mathrm{OH}$ solution were then mixed together, after which the solution was centrifuged at $3000 \times g$ for $10 \mathrm{~min}\left(4^{\circ} \mathrm{C}\right)$. The sediment was then dissolved in $4 \mathrm{~mL}$ of $2 \mathrm{M} \mathrm{H}_{2} \mathrm{SO}_{4}$, and the absorbance was measured at $412 \mathrm{~nm}$. The results were expressed as micromoles per gram.

\subsection{Activities of SOD, CAT and APX}

The activities of $S O D, C A T$ and $A P X$ were measured according to an improved method used by Lin et al. (2014), Zhu et al.
(2013) and Nukuntornprakit et al. (2015). Blueberry tissues were extracted at $4{ }^{\circ} \mathrm{C}$ with $2.5 \mathrm{~mL}$ of $0.05 \mathrm{M}$ sodium phosphate buffer ( $\mathrm{pH} 7.8$ ) comprising $0.1 \mathrm{mM}$ EDTA, and then the mixtures were centrifuged at $12,000 \times \mathrm{g}$ for $30 \mathrm{~min}\left(4^{\circ} \mathrm{C}\right)$. The supernatant was collected and prepared for further experiments.

The SOD activity was measured by following the decrease in absorbance at $560 \mathrm{~nm}$. One enzymatic unit of SOD activity was defined as $50 \%$ inhibition of the reduction in NBT per minute (Lin et al., 2014). The results were expressed in units per gram (Zhao et al., 2020).

The CAT activity was measured according to the decrease in absorbance at $240 \mathrm{~nm}$ and recorded for $5 \mathrm{~min}$. One enzymatic unit of CAT activity was defined as the decomposition of $1 \mathrm{mM} \mathrm{H}_{2} \mathrm{O}_{2}$ per minute ( $\mathrm{Zhu}$ et al., 2013). The results were expressed as units per gram (Zhao et al., 2020).

The APX activity was measured according to the decrease in absorbance at $290 \mathrm{~nm}$ and recorded for $5 \mathrm{~min}$. One enzymatic unit of APX activity was defined as the oxidization of $1 \mathrm{mM}$ ascorbic acid per minute (Nukuntornprakit et al., 2015). The results were expressed as units per gram (Zhao et al., 2020).

\subsection{Statistical analysis}

All the experiments were conducted in accordance with a completely randomized design. All the data were recorded as the means of three replicates, and all statistical analyses were conducted via SPSS 16.0 software. Pairwise comparisons were performed by Student's t-tests, and multiple comparisons were computed by Duncan's tests. Differences at $p<0.05$ were considered significant.

\section{Results}

\subsection{Weight loss and firmness of blueberries}

The changes in weight loss and firmness of blueberries treated with 1-MCP, CA and 1-MCP+CA are shown in Figure 1. Weight loss experienced a significant increase during the 80-day storage period in all the samples, but 1-MCP, CA and 1-MCP+CA inhibited the increase, while the combination of 1-MCP and CA treatment resulted in the most effective inhibition. At 80 days of storage, weight loss under the control
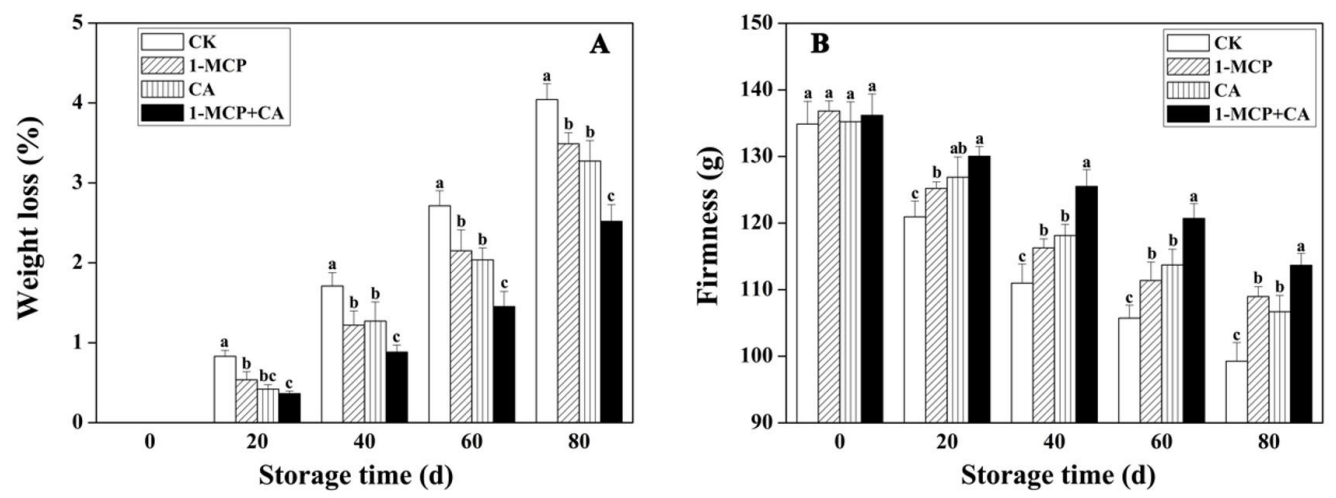

Figure 1. Effects of 1-MCP, CA and 1-MCP + CA treatments on weight loss (A) and firmness (B) of blueberry fruit during storage at $0{ }^{\circ} \mathrm{C}$ for 80 days. Data stand for the means value of three biological replicates and their standard errors. Different letters indicate significant differences according to student's t-test at $p<0.05$. 
treatment was $4.04 \%$, while the weight losses under the 1-MCP, $\mathrm{CA}$ and 1-MCP + CA treatments were 3.49\%, 3.27\%, and 2.52\%, respectively (Figure 1A). Consistently, although higher levels of fruit firmness were shown under the 1-MCP or CA treatment than under the control treatment, the 1-MCP + CA treatment was found to be the most effective at reducing the firmness of blueberries throughout the whole storage time (Figure 1B). These results indicated that the application of 1-MCP, CA or $1-\mathrm{MCP}+\mathrm{CA}$ reduced the increase in weight loss and inhibited the firmness reduction in blueberries.

\subsection{TSS and TA contents of blueberries}

The TSS content in the control samples showed a steady but slightly increasing trend during the first 20 days of storage, peaking at $15.98 \%$, after which it decreased during the rest of the storage period, which resulted in the lowest value at day 80. The blueberries under the 1-MCP, CA and 1-MCP + CA treatment displayed a significantly slower rate in the reduction in TSS content compared to that of the control blueberries from day 60 to day 80 (Figure 2A).

Treatment with $1-\mathrm{MCP}+\mathrm{CA}$ significantly $(\mathrm{p}<0.05)$ suppressed the decrease in TA content in the blueberries (Figure 2B). The TA content in the control samples decreased by $25.9 \%$ at day 80 compared with day 0 , while the decreases in the fruits under the 1-MCP, CA and 1-MCP + CA treatments were only $19.5 \%, 21.9 \%$ and $14.7 \%$, respectively, during the same period. Indeed, the treatment of 1-MCP, CA and 1-MCP + CA effectively influenced the TSS and TA contents of blueberries throughout the storage period.

\subsection{Relative electrolyte leakage and MDA content of blueberries}

Changes in relative electrolyte leakage are shown in Figure 3A. Blueberries without any treatment presented a marked increase, but in the treated samples, the leakage increased to varying degrees under the different treatments during storage. The relative electrolyte leakage in the control fruits increased

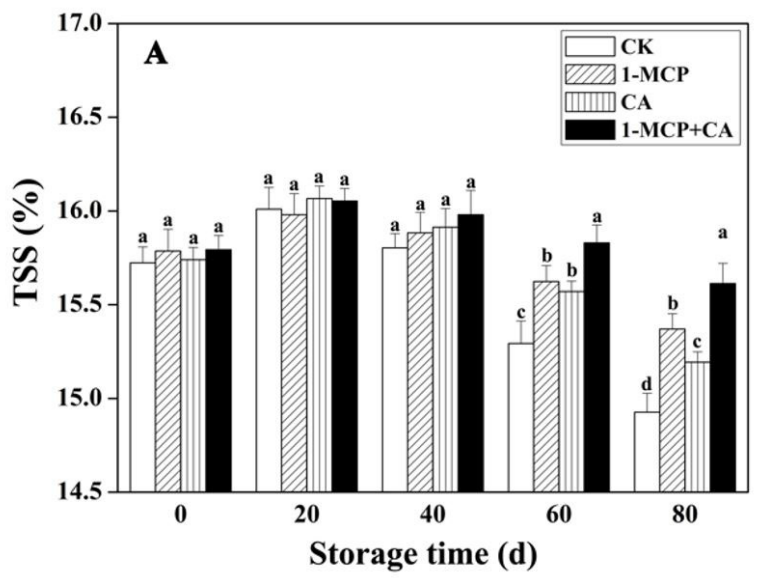

by 1.65 -fold at day 80 compared to day 0 , while the increase in fruits under the 1-MCP + CA treatment was only 1.33-fold during the same period. Moreover, the application of 1-MCP, $\mathrm{CA}$ and 1-MCP + CA reduced the accumulation of MDA. The maximum MDA content in the control fruit samples at day 80 was $13.67 \mu \mathrm{mol} \cdot \mathrm{g}^{-1}$, while that in the fruit samples under the $1-\mathrm{MCP}+\mathrm{CA}$ treatment was only $9.58 \mu \mathrm{mol} \cdot \mathrm{g}^{-1}$ on the same day of storage (Figure 3B).

\section{4 $\mathrm{O}_{2}^{-\cdot}$ production and $\mathrm{H}_{2} \mathrm{O}_{2}$ content in the blueberries}

Figure 4A shows that $\mathrm{O}_{2}^{-}$production changed slowly throughout the beginning of storage, while it showed a rapid increase in all the samples after 40 days. Treatments including 1-MCP, CA and 1-MCP + CA inhibited the increasing rate of $\mathrm{O}_{2}^{-}$. The production in the control fruits increased by $71.3 \%$ on day 80 compared to day 0 , while that in the fruits in the 1-MCP, CA and 1-MCP + CA groups increased by $64.0 \%, 66.7 \%$ and $59.0 \%$, respectively, during the same period. Significant differences were found on days 40,60 and 80 between the control and treated blueberries. Correspondingly, $\mathrm{H}_{2} \mathrm{O}_{2}$ accumulation in the blueberries increased with the prolonging of storage time, but 1-MCP, CA and 1-MCP + CA effectively delayed this process. At 80 days of storage, the $\mathrm{H}_{2} \mathrm{O}_{2}$ content in the control blueberries was $10.45 \mu \mathrm{mol} \cdot \mathrm{g}^{-1}$, which was $1.33-$, 1.17 - and 1.60-fold higher than that in the blueberries under the 1-MCP-, CA- and 1-MCP + CA-treatments, respectively. These results indicated that the 1-MCP, CA and 1-MCP + CA treatments slowed the $\mathrm{O}_{2}^{-}$production increase and reduced the $\mathrm{H}_{2} \mathrm{O}_{2}$ accumulation, as shown in Figure $4 \mathrm{~B}$, and significant differences were detected between the control and treated fruits after 40 days of storage time. Importantly, the combination of 1-MCP and CA had the most remarkable effects.

\subsection{Antioxidant enzyme activities in blueberries}

The activities of antioxidant enzymes including SOD, CAT and APX are presented in Figure 5. The SOD activity in blueberries increased in all the samples before 40 days but

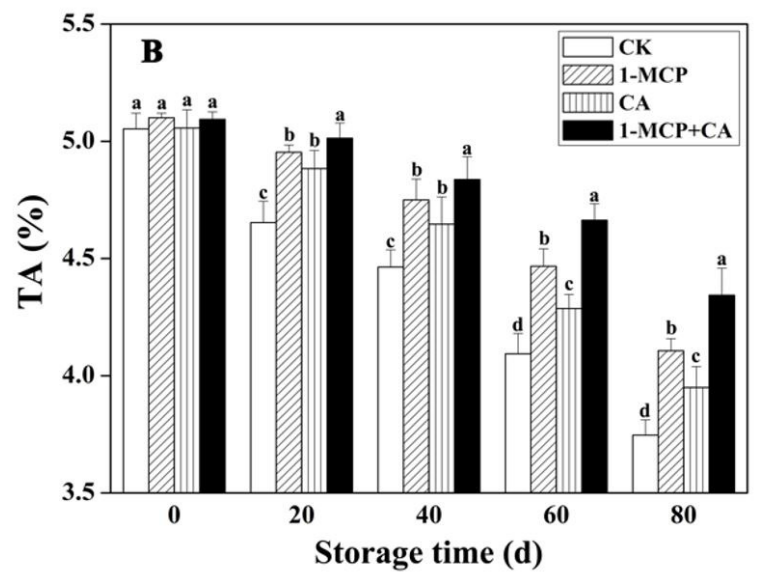

Figure 2. Effects of 1-MCP, CA and 1-MCP + CA treatments on TSS (A) and TA (B) contents of blueberry fruit during storage at $0{ }^{\circ} \mathrm{C}$ for 80 days. Data stand for the means value of three biological replicates and their standard errors. Different letters indicate significant differences according to student's t-test at $p<0.05$. 

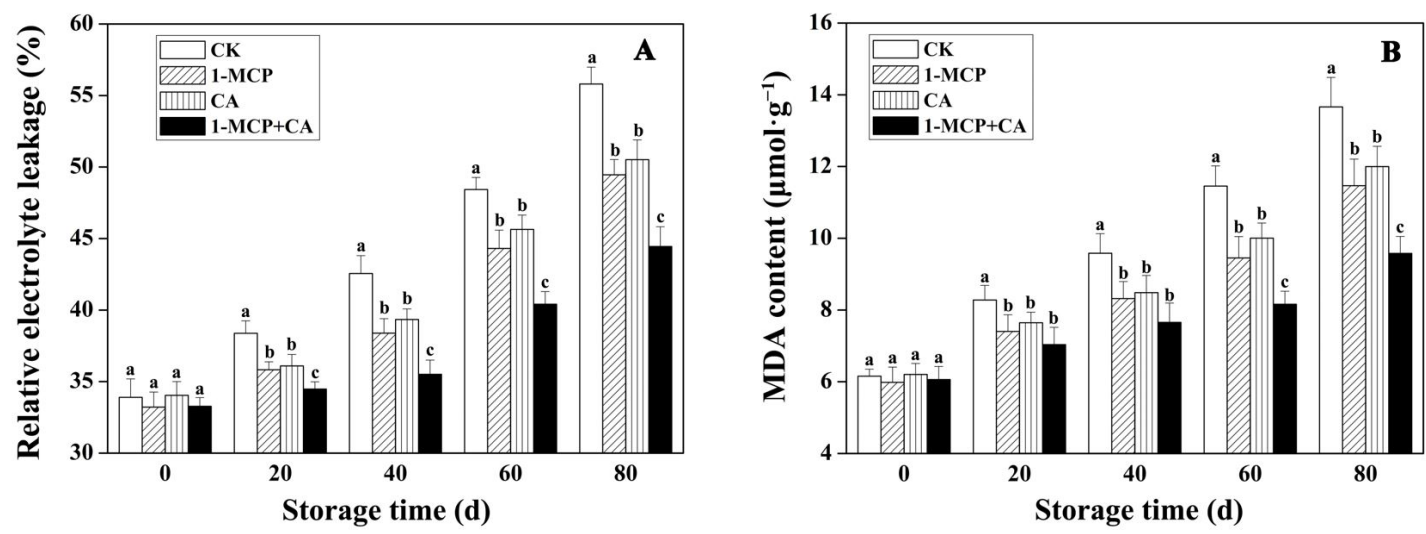

Figure 3. Effects of 1-MCP, CA and 1-MCP + CA treatments on relative electrolyte leakage (A) and MDA content (B) of blueberry fruit during storage at $0{ }^{\circ} \mathrm{C}$ for 80 days. Data stand for the means value of three biological replicates and their standard errors. Different letters indicate significant differences according to student's t-test at $p<0.05$.
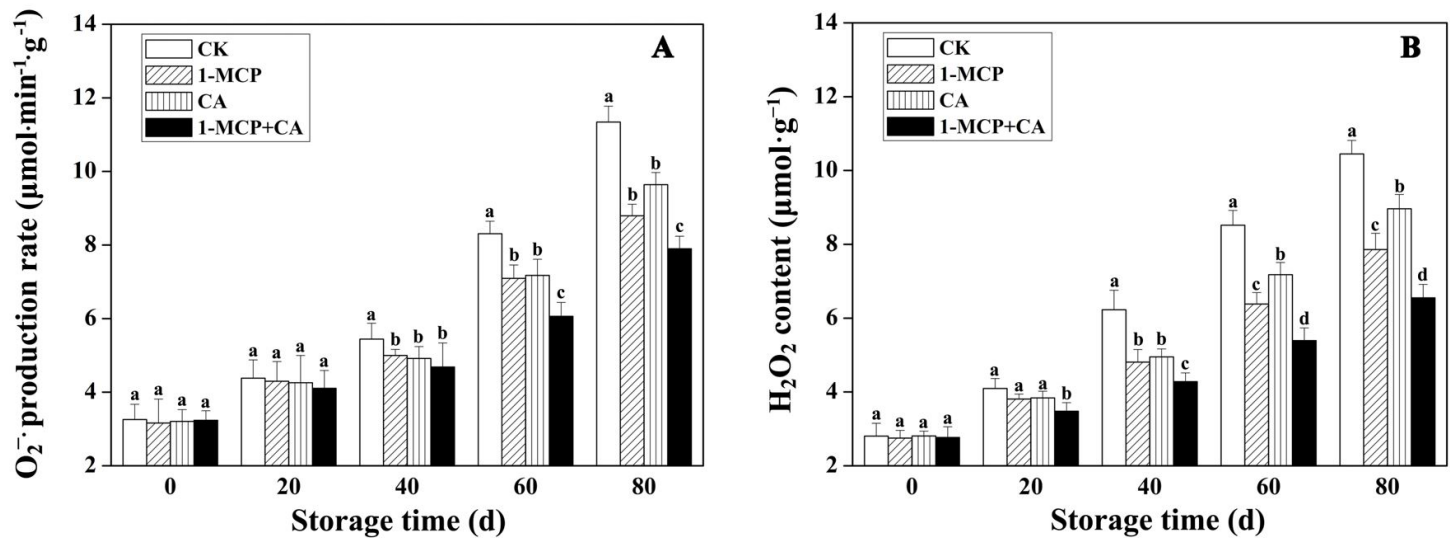

Figure 4. Effects of 1-MCP, CA and 1-MCP + CA treatments on $\mathrm{O}_{2}^{-}$production (A) and $\mathrm{H}_{2} \mathrm{O}_{2}$ content (B) of blueberry fruit during storage at $0{ }^{\circ} \mathrm{C}$ for 80 days. Data stand for the means value of three biological replicates and their standard errors. Different letters indicate significant differences according to student's t-test at $p<0.05$.

decreased afterward, and higher activities of SOD in treated blueberries compared with control samples were observed throughout the whole storage time (Figure 5A).

Figure 5B illustrates that the CAT activity in all the blueberries displayed a dramatic increase from day 20 to day 40 of storage, followed by a decrease during the rest of the storage time. The maximum CAT activity was recorded in the 1-MCP + CAtreated blueberries on day 40 , which was $45.60 \%, 27.53 \%$ and $16.66 \%$ higher than the activity in the control samples on the same day of storage time. Moreover, higher CAT activities in the 1-MCP-, CA- and 1-MCP + CA-treated blueberries were found in comparison with the activity in the control fruits throughout the storage period.

Similarly, 1-MCP, CA and 1-MCP + CA treatment effectively stimulated the increase in APX activity during the first 40 days of storage (Figure 5C). On day 40, the APX activity in the control and 1-MCP + CA-treated samples increased by $33.2 \%$ and $45.3 \%$, respectively. Afterwards, a rapid decrease in APX activity was detected after 40 days in all the blueberries, but the application of 1-MCP, CA and 1-MCP + CA effectively delayed this decrease. These results indicated that the 1-MCP, CA and 1-MCP + CA treatments enhanced the activities of antioxidant enzymes, including SOD, CAT and APX, in the initial storage period, and these activities were maintained at higher levels during the middle and late storage periods compared to those in the controls. Compared with the other treatments, 1-MCP + CA was found to be the most effective treatment for improving antioxidant enzyme activities.

\section{Discussion}

Powderblue blueberry used in our study is a cultivar of the highbush blueberry species, and it is a local cultivar grown in Guizhou Province, China. Compared with those of other highbush species, Powderblue fruits are firmer and have a longer shelflife. The firmness of Powderblue blueberries was $135 \mathrm{~g} \cdot \mathrm{mm}^{-1}$ on the day of harvest, which is higher than that of most highbush species (Ehlenfeldt \& Martin, 2002). In addition, the weight loss of Lateblue was $4.4 \%$ in the non-treated group at 35 days (Chiabrando \& Giacalone, 2011), and that of LanFeng was nearly $5 \%$ of that of control berries at 60 days (Zhou et al., 2014); however, the weight loss of the control fruits of Powderblue in our 

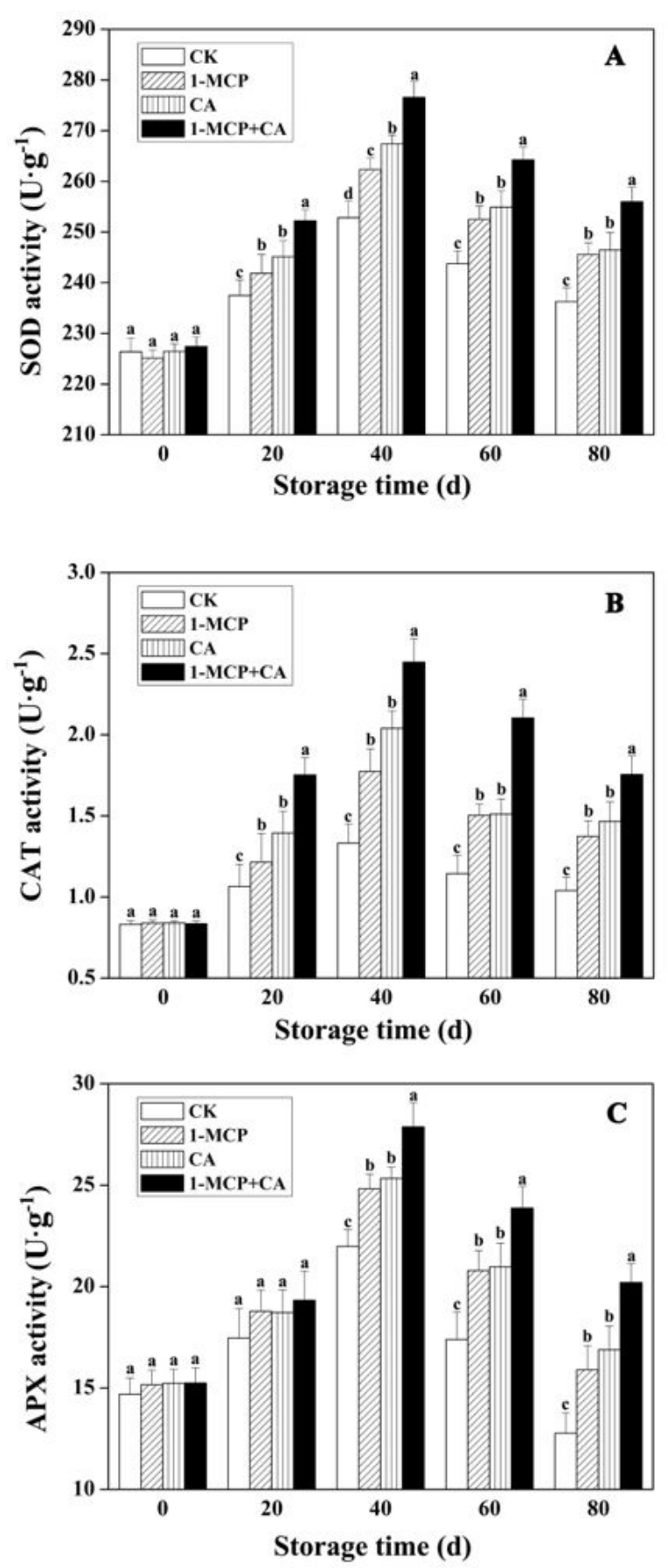

Figure 5. Effects of 1-MCP, CA and 1-MCP + CA treatments on the activities of SOD (A), CAT (B) and APX (C) enzymes of blueberry fruit during storage at $0{ }^{\circ} \mathrm{C}$ for 80 days. Data stand for the means value of three biological replicates and their standard errors. Different letters indicate significant differences according to student's t-test at $p<0.05$.

study was only $4.0 \%$ at 80 days (Figure $1 \mathrm{~A}$ ). Thus, physiological changes in Powderblue fruits were observed throughout the 80 days of storage.

Our investigations aimed to elucidate the optimum 1-MCP, $\mathrm{CA}$ and 1-MCP + CA treatment that maintained the quality of postharvest blueberries. Weight loss, firmness, and the contents of TSS and TA are widely used to evaluate the sensory qualities of postharvest fruit throughout the storage period. Thus, these physical indexes were used to evaluate the changes in blueberries during storage at $0{ }^{\circ} \mathrm{C}$ for 80 days. As shown in Figure 1, 1-MCP or CA treatment partially controlled the weight loss and firmness reduction, but the combination of $1-\mathrm{MCP}$ and $\mathrm{CA}$ treatment was determined to be the most important for suppressing water loss and the softening process, which resulted in the lowest weight loss and highest firmness throughout the storage period. Similar results were described in previous reports in which 1-MCP pretreatment of harvested southern highbush blueberries could decrease fruit firmness and maintain weight loss (Blaker \& Olmstead, 2014; Chiabrando \& Giacalone, 2011). In addition, the TSS and TA contents were further explored in this experiment. As shown in Figure 2, it was found that the TSS and TA contents under the different treatments performed in a similar way and stably decreased during the storage period in all the blueberries, but the treatments effectively inhibited the reduction. Consistently, higher TA values were detected in harvested Lateblue blueberries samples that were treated with 1-MCP and controlled atmosphere $(3 \mathrm{kPa} \mathrm{O}+11 \mathrm{kPa}$ $\mathrm{CO}_{2}$ ) compared with control blueberries during storage time (Chiabrando \& Giacalone, 2011). Zhu et al. (2013) reported that a controlled atmosphere (CA) $\left(2 \% \mathrm{O}_{2}+1 \% \mathrm{CO}_{2}\right)$ did not alter the TSS content but could impair the softening of harvested apple fruits stored at $0{ }^{\circ} \mathrm{C}$.

Since the postharvest blueberries were stored in a lowtemperature environment $\left(0^{\circ} \mathrm{C}\right)$, the changes in the relative electrolyte leakage and MDA content were investigated to evaluate the cell membrane permeability and cold sensitivity of blueberries samples. MDA, one of the products of lipid peroxidation, is used to estimate the degree of membrane lipid peroxidation. Relative electrolyte leakage is considered to be a marker for indicating the integrity of membrane structure. MDA content and cell membrane electrolyte leakage were elevated during blueberry lowtemperature storage, indicating increased lipid peroxidation and membrane damage (Zhou et al., 2014). Membrane permeability changes were observed by measuring electrolyte leakage intensity during storage according to the methods of Li et al. (2011); the MDA content and membrane permeability increased, implying that membrane integrity was damaged during sweet pepper storage (Li et al., 2011). In our study, as shown in Figure 3A, the MDA content in all the blueberries tended to increase with increasing storage time, but the application of 1-MCP, CA and 1-MCP + CA effectively maintained the accumulation of MDA, which was similar to the changes in relative electrolyte leakage (Figure $3 \mathrm{~B}$ ). During storage at $0{ }^{\circ} \mathrm{C}$ for 80 days, the application of 1-MCP, CA and 1-MCP + CA enhanced the cold tolerance of the blueberries, as indicated by the reduced relative electrolyte leakage and MDA accumulation, and the combined treatment was more effective than both single treatments at improving cold tolerance. The results of our study are consistent with those of previous studies. Furthermore, 1-MCP treatment decreased chilling injury (CI) of persimmon that was stored at $1{ }^{\circ} \mathrm{C}$ by protecting cell structure integrity (Tessmer et al., 2019). Treatment with modified-atmosphere packaging (MAP) and 1-MCP markedly delayed the CI symptoms of cold-stored sweet persimmon; compared with the control fruits, the treated fruits showed lower electrolyte leakage and lower MDA content, and 
the MAP + 1-MCP treatment had better effects than did the $1-\mathrm{MCP}$ treatment at maintaining fruit quality and reducing cold sensitivity (Zhao et al., 2020). In general, the improved cold tolerance and the enhanced integrity of cell membrane structure have been associated with the effects of 1-MCP and CA treatment.

It has been reported that blueberry pomace is a source of fiber with antioxidant capacity in the blueberry juice product industry, which suggest the importance of antioxidant capacity in blueberry fruits (Tagliani et al., 2019). Fruit quality maintenance is associated with the accumulation of ROS, including superoxide radical $\left(\mathrm{O}_{2}^{-}\right), \mathrm{OH}^{-}$(hydroxyl radical) and $\mathrm{H}_{2} \mathrm{O}_{2}$ (hydrogen peroxide). Excessive accumulation of ROS and MDA can induce membrane lipid peroxidation, damage membrane structural integrity and stimulate fruit senescence (Lin et al., 2014; Sun et al., 2018). Therefore, the scavenging of ROS relies on the action of antioxidant enzymes such as SOD, CAT and APX. The conversion from $\mathrm{O}_{2}$ to $\mathrm{H}_{2} \mathrm{O}_{2}$ is catalysed by SOD, and then $\mathrm{H}_{2} \mathrm{O}_{2}$ is converted to $\mathrm{O}_{2}$ and $\mathrm{H}_{2} \mathrm{O}$ by CAT and APX (Mittler, 2002). Previous works have suggested that 1-MCP treatment affects the activities of antioxidant enzymes in green pepper fruits, which were obviously higher than the activities in control fruits during 10 days of storage (Cao et al., 2012). The induction of pericarp browning in response to exogenous $\mathrm{H}_{2} \mathrm{O}_{2}$ treatment of harvested longan fruits involved $\mathrm{O}_{2}$ production, $\mathrm{H}_{2} \mathrm{O}_{2}$ accumulation and antioxidant enzyme activity reduction (Lin et al., 2014). In this study, the production of $\mathrm{O}_{2}^{--}$and $\mathrm{H}_{2} \mathrm{O}_{2}$ in blueberries increased throughout the whole storage period, but the production was effectively delayed by $1-\mathrm{MCP}, \mathrm{CA}$ and $1-\mathrm{MCP}$ + CA treatment (Figure 4). On the other hand, the activities of SOD, CAT and APX in blueberries increased markedly before day 40 of storage but declined continuously thereafter, while the application of 1-MCP, CA and 1-MCP + CA enhanced the activities of ROS-scavenging enzymes throughout the whole storage duration. Among all the treatments and the control, the 1-MCP + CA treatment was the best at controlling membrane lipid peroxidation in the blueberries (Figure 5). Thus, it can be concluded that, in the treated blueberries, the stimulated activities of SOD, CAT and APX resulted in the inhibition of $\mathrm{O}_{2}^{-}$production and $\mathrm{H}_{2} \mathrm{O}_{2}$ accumulation, ultimately leading to effective $\mathrm{ROS}$ scavenging and fruit quality maintenance during the 80 days of storage.

1-MCP is an ethylene receptor blocker and limits fruit senescence induced by ethylene. Therefore, 1-MCP treatment effectively maintained blueberry quality and enhanced the antioxidant potential ( $\mathrm{Li}$ et al., 2011). On the other hand, a controlled atmosphere (CA) can reduce $\mathrm{O}_{2}$ and elevate $\mathrm{CO}_{2}$, maintaining the freshness of harvested blueberries by inhibiting their respiration rate, metabolic activity, ethylene production, and physiological deterioration during the storage period (Zhao et al., 2020). The interaction effects of CA and 1-MCP were investigated compared with the main effects of single applications of 1-MCP or CA. It was found that the combined treatment of $\mathrm{CA}$ and 1-MCP was the most effective at prolonging blueberry shelf-life. This influence may have occurred because the low-ethylene, low- $\mathrm{O}_{2}$ and high- $\mathrm{CO}_{2}$ environment created by the 1-MCP and CA combination treatment maintains firmness, maintains TSS and TA contents, reduces weight loss, protects

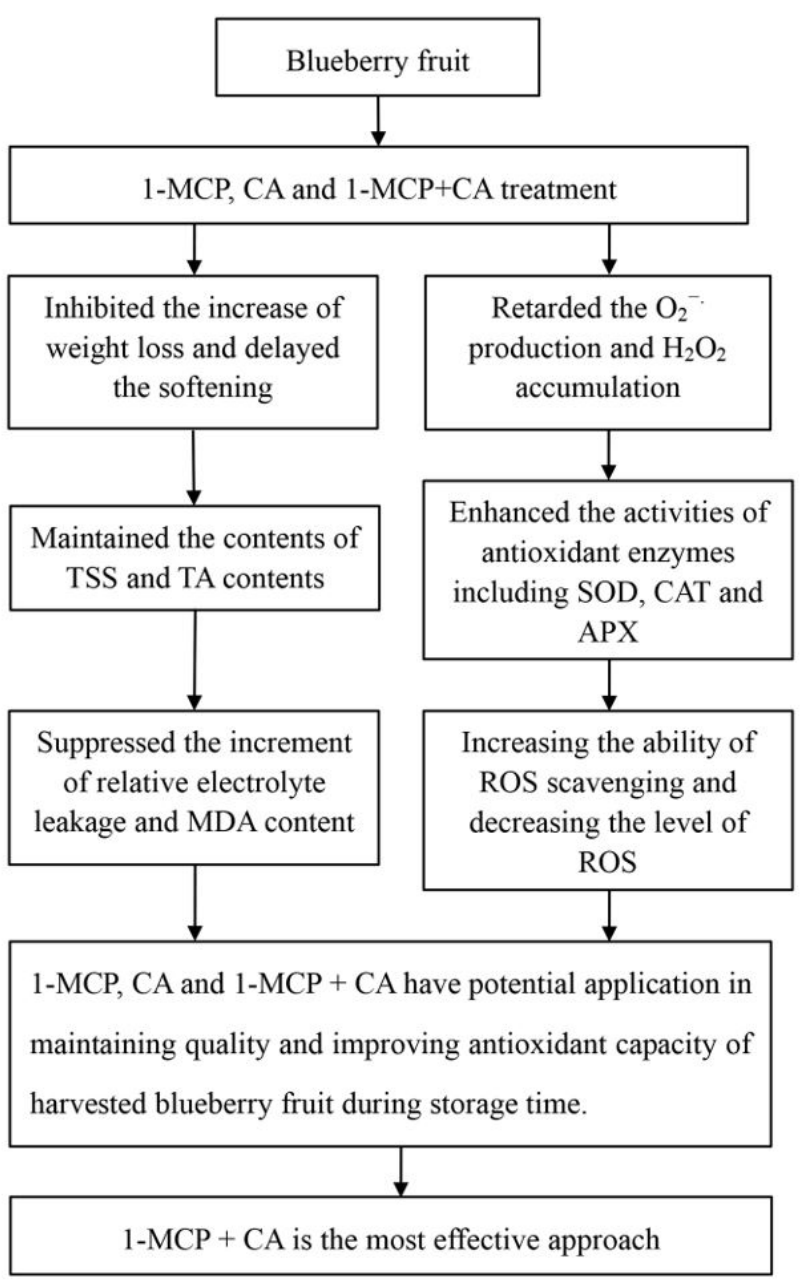

Figure 6. The probable mechanism of 1-MCP, CA and 1-MCP + CA treatments-improved fruit quality of harvested blueberry fruit through modulating the levels of ROS production and scavenging.

membrane integrity, modulates ROS production levels and enhances the activities of antioxidant enzymes. The probable mechanism responsible is summarized in Figure 6.

\section{Conclusion}

In this study, the effects of 1-MCP, CA and 1-MCP + CA on the quality and antioxidant capacity of postharvest blueberries were evaluated. It was found that 1-MCP, CA and 1-MCP + CA inhibited the increase in weight loss, delayed the softening of fruit and maintained the contents of TSS and TA of blueberries during storage at $0{ }^{\circ} \mathrm{C}$ for 80 days. The applications of $1-\mathrm{MCP}$, $\mathrm{CA}$ and 1-MCP + CA also suppressed the increase in relative electrolyte leakage and MDA content; slowed $\mathrm{O}_{2}^{-}$production and $\mathrm{H}_{2} \mathrm{O}_{2}$ accumulation; and enhanced the activities of antioxidant enzymes such as SOD, CAT and APX. Thus, the effects of 1-MCP, CA and 1-MCP + CA treatment on improving the quality of harvested blueberries may contribute to the enhancement of antioxidant capacity. Importantly, our results indicated that, compared with individual 1-MCP or CA treatments, the combination of 1-MCP and CA treatment may be the most effective application for the preservation of postharvest blueberries. 1-MCP + CA treatment 
could be a safe, eco-friendly, and sustainable approach for the blueberry industry.

\section{Acknowledgements}

This research was supported by Guizhou Province Undergraduate Colleges and Universities Serving the Agricultural Industry Revolution Strategic Action Plan Project (Department of Education of Guizhou Province [2018]090); the Program for Department of Science and Technology of Guizhou Province, China [2019]4221); and Tianjin Academy of Agricultural Sciences Youth Innovation Project (2019009). This work was financially supported by Discipline and Master's Site Construction Project of Guiyang University by Guiyang City Financial Support Guiyang University [SY-2020].

\section{References}

Blaker, K. M., \& Olmstead, J. W. (2014). Effects of preharvest applications of 1-methylcyclopropene on fruit firmness in southern highbush blueberry. Acta Horticulturae, (1017), 71-75. http://dx.doi.org/10.17660/ ActaHortic.2014.1017.5.

Cao, S. F., Yang, Z. F., \& Zheng, Y. H. (2012). Effect of 1-methylcyclopene on senescence and quality maintenance of green bell pepper fruit during storage at $20^{\circ} \mathrm{C}$. Postharvest Biology and Technology, 70, 1-6. http://dx.doi.org/10.1016/j.postharvbio.2012.03.005.

Chen, Y. H., Sun, J. Z., Lin, H. T., Hung, Y. C., Zhang, S., Lin, Y. F., \& Lin, T. (2017). Paper-based 1-MCP treatment suppresses cell wall metabolism and delays softening of huanghua pears during storage. Journal of the Science of Food and Agriculture, 97(8), 2547-2552. http://dx.doi.org/10.1002/jsfa.8072. PMid:27706823.

Chiabrando, V., \& Giacalone, G. (2011). Shelf-life extension of highbush blueberry using 1-methylcyclopropene stored under air and controlled atmosphere. Food Chemistry, 126(4), 1812-1816. http://dx.doi. org/10.1016/j.foodchem.2010.12.032. PMid:25213961.

Ehlenfeldt, M. K., \& Martin., R. B. Jr. (2002). A Survey of Fruit Firmness in Highbush Blueberry and Species-introgressed Blueberry Cultivars [J]. HortScience, 37(2), 386-389. http://dx.doi.org/10.21273/ HORTSCI.37.2.386.

Han, C., Zuo, J. H., Wang, Q., Xu, L. J., Wang, Z. S., Dong, H. Z., \& Gao, L. P. (2015). Effects of 1-MCP on postharvest physiology and quality of bitter melon (Momordica charantia L.). Scientia Horticulturae, 182, 86-91. http://dx.doi.org/10.1016/j.scienta.2014.07.024.

Hancock, J., Callow, P., Serce, S., Hanson, E., \& Beaudry, R. (2008). Effect of cultivar, controlled atmosphere storage, and fruit ripeness on the long-term storage of highbush blueberries. HortTechnology, 18(2), 199-205. http://dx.doi.org/10.21273/HORTTECH.18.2.199.

Li, L., Lv, F. Y., Guo, Y. Y., \& Wang, Z. Q. (2016). Respiratory pathway metabolism and energy metabolism associated with senescence in postharvest Broccoli (Brassica oleracea $\mathrm{L}$. var. italica) florets in response to $\mathrm{O}_{2} / \mathrm{CO}_{2}$ controlled atmospheres. Postharvest Biology and Technology, 111,330-336. http://dx.doi.org/10.1016/j.postharvbio.2015.09.032.

Li, M., Li, X. A., Li, J., Ji, Y., Han, C., Jin, P., \& Zheng, Y. H. (2018). Responses of fresh-cut strawberries to ethanol vapor pretreatment: improved quality maintenance and associated antioxidant metabolism in gene expression and enzyme activity levels. Journal of Agricultural and Food Chemistry, 66(31), 8382-8390. http://dx.doi.org/10.1021/ acs.jafc.8b02647. PMid:30011987.

Li, X. A., Long, Q. H., Gao, F., Han, C., Jin, P., \& Zheng, Y. H. (2017). Effect of cutting styles on quality and antioxidant activity in fresh- cut pitaya fruit. Postharvest Biology and Technology, 2017(124), 1-7. http://dx.doi.org/10.1016/j.postharvbio.2016.09.009.

Li, X. H., Yun, J., Fan, X. T., Xing, Y. G., \& Tang, Y. (2011). Effect of 1-methylcyclopropene and modified atmosphere packaging on chilling injury and antioxidative defensive mechanism of sweet pepper. African Journal of Biotechnology, 10, 6581-6589. http:// dx.doi.org/10.1007/s10341-011-0141-8.

Lin, Y. X., Lin, H. T., Fan, Z. Q., Wang, H., Lin, Y. F., Chen, Y., Hung, Y.-C., \& Lin, Y. (2020). Inhibitory effect of propyl gallate on pulp breakdown of longan fruit and its relationship with ROS metabolism. Postharvest Biology and Technology, 168, 111272. http://dx.doi. org/10.1016/j.postharvbio.2020.111272.

Lin, Y. X., Lin, H. T., Zhang, S., Chen, Y. H., Chen, M. S., \& Lin, Y. F. (2014). The role of active oxygen metabolism in hydrogen peroxideinduced pericarp browning of harvested longan fruit. Postharvest Biology and Technology, 96, 42-48. http://dx.doi.org/10.1016/j. postharvbio.2014.05.001.

Maclean, D. D., \& Nesmith, D. S. (2011). Rabbiteye blueberry postharvest fruit quality and stimulation of ethylene production by 1-methylcyclopropene. Hortence, 46(9), 1278-1281. http://dx.doi. org/10.21273/HORTSCI.46.9.1278.

Mittler, R. (2002). Oxidative stress, antioxidants and stress tolerance. Trends in Plant Science, 7(9), 405-410. http://dx.doi.org/10.1016/ S1360-1385(02)02312-9. PMid:12234732.

Nilsson, T. (2005). Effects of ethylene and 1-MCP on ripening and senescence of European seedless cucumbers. Postharvest Biology and Technology, 36(2), 113-125. http://dx.doi.org/10.1016/j. postharvbio.2004.11.008.

Nukuntornprakit, O. A., Chanjirakul, K., Van Doorn, W. G., \& Siriphanich, J. (2015). Chilling injury in pineapple fruit: fatty acid composition and antioxidant metabolism. Postharvest Biology and Technology, 99, 20-26. http://dx.doi.org/10.1016/j.postharvbio.2014.07.010.

Oz, A. T., \& Ulukanli, Z. (2014). The effects of calcium chloride and 1-methylcyclopropene (1-MCP) on the shelf life of mulberries (Morus ALBA L.). Journal of Food Processing and Preservation, 38(3), 1279-1288. http://dx.doi.org/10.1111/jfpp.12089.

Saxena, A., Saxena, T. M., Raju, P. S., \& Bawa, A. S. (2013). Effect of controlled atmosphere storage and chitosan coating on quality of fresh-cut jackfruit bulbs. Food and Bioprocess Technology, 6(8), 2182-2189. http://dx.doi.org/10.1007/s11947-011-0761-x.

Sun, J. Z., Lin, H. T., Zhang, S., Lin, Y., Wang, H., Lin, M., Hung, Y. C., \& Chen, Y. (2018). The roles of ROS production-scavenging system in Lasiodiplodia theobromae (Pat.) Griff. \& Maubl.-induced pericarp browning and disease development of harvested longan fruit. Food Chemistry, 247(5), 16-22. http://dx.doi.org/10.1016/j. foodchem.2017.12.017. PMid:29277223.

Tagliani, C., Perez, C., Curutchet, A., Arcia, P., \& Cozzano, S. (2019). Blueberry pomace, valorization of an industry by-product source of fibre with antioxidant capacity. Food Science and Technology, 39(3), 644-651. http://dx.doi.org/10.1590/fst.00318.

Tao, S. C., Chu, H. L., Chen, X. M., Yuan, H. W., Qiu, L. L., Zhao, L., Yan, D., \& Zheng, B. (2017). Study of the effects of 1-MCP to blueberry under cold storage. IOP Conference Series: Earth and Environmental Science, 61, 012041. http://dx.doi.org/10.1088/1755-1315/61/1/012041.

Tessmer, M. A., Appezzato-da-Gloria, B., \& Kluge, R. A. (2019). Evaluation of storage temperatures to astringency 'Giombo' persimmon: storage at $1{ }^{\circ} \mathrm{C}$ combined with $1-\mathrm{MCP}$ is recommended to alleviate chilling injury. Scientia Horticulturae, 257, 108675. http://dx.doi.org/10.1016/j. scienta.2019.108675. 
Van de Velde, F., Esposito, D., Overall, J., Méndez-Galarraga, M. P., Grace, M., Pirovani, M. E., \& Lila, M. A. (2019). Changes in the bioactive properties of strawberries caused by the storage in oxygen- and carbon dioxide-enriched atmospheres. Food Science \& Nutrition, 7(8), 25272536. http://dx.doi.org/10.1002/fsn3.1099. PMid:31428340.

Wang, Y. S., Luo, Z. S., Huang, X. D., Yang, K. L., Gao, S. J., \& Du, R. X. (2014). Effect of exogenous $\gamma$-aminobutyric acid (GABA) treatment on chilling injury and antioxidant capacity in banana peel. Scientia Horticulturae, 168, 132-137.http://dx.doi.org/10.1016/j.scienta.2014.01.022.

Xie, G. F., Wang, X. H., Wei, K. H., Wang, R., Cao, S., Ji, N., \& Yang, Z. Y. (2018). Effects of 1-methylcyclopropene on texture properties of Rabbiteye blueberry during long-term storage and simulated transportation. Food Science and Technology (Campinas), 38(2), 188-192. http://dx.doi.org/10.1590/1678-457x.21816.

$\mathrm{Xu}, \mathrm{F}$, \& Liu, S. (2017). Control of postharvest quality in blueberry fruit by combined 1-methylcyclopropene (1-MCP) and UV-C irradiation. Food and Bioprocess Technology, 10(9), 1-9. http://dx.doi. org/10.1007/s11947-017-1935-y.

Zhao, Q., Jin, M., Guo, L., Pei, H., Nan, Y., \& Rao, J. (2020). Modified atmosphere packaging and 1-methylcyclopropene alleviate chilling injury of 'Youhou' sweet persimmon during cold storage. Food Packaging and Shelf Life, 24, 100479. http://dx.doi.org/10.1016/j. fpsl.2020.100479.

Zhou, Q., Ma, C., Cheng, S. C., Wei, B. D., Liu, X. Y., \& Ji, S. J. (2014). Changes in antioxidative metabolism accompanying pitting development in stored blueberry fruit. Postharvest Biology and Technology, 88, 88-95. http://dx.doi.org/10.1016/j.postharvbio.2013.10.003.

Zhu, Z., Liu, R. L., Li, B. Q., \& Tian, S. P. (2013). Characterisation of genes encoding key enzymes involved in sugar metabolism of apple fruit in controlled atmosphere storage. Food Chemistry, 141(4), 3323-3328. http://dx.doi.org/10.1016/j.foodchem.2013.06.025. PMid:23993488. 